\title{
Coadministration of Ginger Roots Extract and Vitamin E Improves Male Fertility of Streptozotocin-Induced Diabetic Rats
}

\author{
Mostafa Abbas Shalaby ${ }^{1 *}$, Rehab Ali Ghandour ${ }^{2}$ and Shimaa Ramadan Emam ${ }^{1}$ \\ ${ }^{1}$ Department of Pharmacology, Faculty of Veterinary Medicine, Cairo University, Giza, Egypt \\ ${ }^{2}$ Department of Physiology, Faculty of Veterinary Medicine, Cairo University, Giza Egypt \\ *Corresponding author: m_shalaby_1@ outlook.com
}

\begin{abstract}
\begin{tabular}{llll}
\hline Article History: 21-338 & Received: 17-Jun-21 & Revised: 20-Jul-21 & Accepted: 30-Jul-21
\end{tabular}
\section{ABSTRACT}

Ginger is an important medicinal plant in folk medicine. Antioxidant, antidiabetic, and anti-inflammatory effects have been reported in ginger extracts. This study was performed to examine how ginger extract (GE) and vitamin E (Vit E) have affected the fertility in Streptozotocin-induced diabetic male rats. Sixty adult male rats were randomly assigned into six groups $(n=10)$. Group 1 served as a negative control, while the other animals were intraperitoneally injected with Streptozotocin $(50 \mathrm{mg} / \mathrm{kg})$ after fasting for 16 hours to induce diabetes. Group 2 was kept as a diabetic positive control. While groups 3 and 4 were orally given GE alone at 300 and $600 \mathrm{mg} / \mathrm{kg}$ for 65 consecutive days to cover the whole spermatogenic cycle in rats, respectively. For the same period, groups 5 and 6 received GE ( 300 and $600 \mathrm{mg} / \mathrm{kg}$ ) plus Vit E $(200 \mathrm{mg} / \mathrm{kg})$. Serum samples were obtained to estimate blood glucose, insulin, testosterone, FSH, and LH levels. Sex organs have been weighed, besides semen picture and histopathology of the testis were carried out. The results revealed that co-administration of GE and Vit. E increased the fertility index, weights of the testis and epididymis, serum testosterone level and improved semen quality in Streptozotocin-induced diabetic rats. Moreover, co-administration of GE and Vit. E caused hypoglycemia and hypoinsulinemia in administered rats compared to the diabetic positive control. Mild to moderate testicular degeneration and incomplete arrest of spermatogenesis were seen by histopathological examination of diabetic control group. Moreover, GE and Vit. E alleviated testicular lesions induced by diabetes, and improved spermatogenesis in treated groups. Conclusively, diabetic patients who are sexually impotent may benefit from a dietary supplement containing ginger roots and vitamin $\mathrm{E}$.
\end{abstract}

Key words: Male fertility; Ginger; Testis; Testosterone; Sperms; Histopathology; Vitamin E; Glucose.

\section{INTRODUCTION}

Diabetes mellitus (DM) is a disease of inadequate control of blood glucose levels. DM, the most common endocrine disorder, is characterized by persistent hyperglycemia caused when the pancreas fails to secrete insulin (insulin deficiency) or resistance to insulin (insulin resistance), or both. Hyperglycemia occurs when cells are unable to utilize glucose and/or the liver and skeletal muscles are unable to store glycogen (LuisRodríguez et al. 2012). Hyperglycemia induces oxidative stress, by increasing the generation of reactive oxygen species (ROS) and reducing the activity of antioxidant enzymes (Lucchesi et al. 2013). Complications of diabetes, particularly diabetic nephropathy, are strongly influenced by oxidative stress (Wang et al. 2011). Inflammation and oxidative stress are usually linked with diabetes mellitus which leads to multi-organ damages during the course of disease. It is well known that persistent hyperglycemia induces testicular lesions, which adversely affects the process of spermatogenesis and reduces male fertility in Streptozotocin-induced diabetic rat (Kanter et al. 2012).

Male factors account for $40-50 \%$ of reported infertility cases; consequently, it has become a severe public health issue (Isidori et al. 2006). Several factors can impair spermatogenesis and have a negative impact on sperm quality and quantity. Male infertility can be caused by hormonal imbalances, anatomical abnormalities, or exogenous medication exposure. In addition, there are several pathological conditions which have negative impacts on male fertility and sperm production, such as coronary heart disease, chronic liver disease and diabetes (Brezina et al. 2012).

Cite This Article as: Shalaby MA, RA Ghandour and Emam SR, 2022. Coadministration of ginger roots extract and vitamin E improves male fertility of streptozotocin-induced diabetic rats. International Journal of Veterinary Science 11(2): 183-188. https://doi.org/10.47278/journal.ijvs/2021.083 
Ginger (Zingiber officinale) is one of the most common herbal plants which belong to the family Zingiberaceae and is used as a popular spice in various foods and beverages as well as for medicinal purposes (Mekuriya and Mekibib 2018). It was reported that ginger have anti-inflammatory (Mascolo et al. 1989), antidiabetic (Shanmugam et al. 2011) and antioxidant (Joshua and Catherine 2010; Abdel-Azeem et al. 2013), effects. These effects are attributed to gingerols and shogaols exciting in ginger (Zahang et al. 2017; Bakr et al. 2020). Ginger roots ethanolic extract attenuated oxidative stress and gene expression (Sief et al. 2021) and improved sexual performance and fertility of quail birds (Al-Kashef 2021). Ginger is commonly used to treat nausea and vomiting, pain, many types of cancers (Romero et al. 2018; Majeed et al. 2021), osteoarthritis, diabetes mellitus and hyperlipidemia, in Streptozotocin - induced diabetes (AlAmin et al. 2017), and stomach aches (Bodagh et al. 2019). However, Morakinyo et al. (2008) reported the protecting effect of ginger aqueous extract against infertility of male rats is due to its antioxidant and androgenic effects. Zahra and Abbas (2020) mentioned that ginger and Echinacea extracts improve the quality of frozen ram spermatozoa. However, Eid et al. (2017) found that ingredients of ginger roots could alleviate diabetic prostatic complications. Furthermore, Banihani (2018) attributed the possible mechanisms of improved male fertility by ginger extract due to its ability to increase testosterone production, reduce oxidative stress, enhance the activity of antioxidant enzymes, and normalize blood glucose levels. Ginger extract has potential to improve semen quality and quantity in lead acetate-treated male rats (Odo et al. 2020). The purpose of this study was to see how coadministration of GE and Vit. E could affect the male fertility in Streptozotocin-induced diabetic rats.

\section{MATERIALS AND METHODS}

\begin{abstract}
Animals
Sixty adults (200-210g bwt, 3 months old) male Sprague-Dawley rats were used. Rats were obtained from Laboratory Animal Colony, Agricultural Research Center, Giza, Egypt. Animals were housed under hygienic condition at $24^{\circ} \mathrm{C}, 50 \%$ relative humidity and $12 \mathrm{hr}$ light/12hr dark cycles. Rats were fed freely on locally manufactured rat pellets, and water was available at all the times. The experiments were carried out according to rules of International Animal Care and Use Committee at Pharmacology department, Faculty of Veterinary Medicine, Cairo University (Vet. CU. IACUC, dated 16 March 2021).
\end{abstract}

\section{Drugs and chemicals}

Streptozotocin (STZ) (Sigma-Aldrich Chemical Company, St. Louis, MO, USA) is a monofunctional methyl nitrosourea that can induce diabetes mellitus type 1 through its toxic effects on pancreatic beta cells. The administered dose of STZ used in this study was $50 \mathrm{mg} / \mathrm{kg}$ injected by intraperitoneal route daily for 7 days after fasting rats for 16 hours as previously mentioned by Lenzen (2008). STZ was supplied and before the use of STZ, it was freshly prepared by dissolving it in $0.01 \mathrm{M}$ sodium citrate buffer solution with a $\mathrm{pH}$ of 4.5. Vitamin $\mathrm{E}$ (Pharco Company for Pharmaceuticals, Alexandria Egypt) has been provided in form of soft capsules containing $1000 \mathrm{mg}$ of Vit. E. Glucose and insulin radioimmunoassay kits (Gamma Trade Company, Egypt) have been provided for estimating blood glucose and insulin level, respectively.

\section{Induction of diabetes mellitus}

Male rats had been fasted for 16 hours then injected intraperitoneally by Streptozotocin in a dose of $50 \mathrm{mg} / \mathrm{kg}$ (equal to a volume of $1 \mathrm{~mL} / \mathrm{rat}$ ). To prevent STZ-induced hypoglycemia, the rats were given a 5\% sucrose solution overnight. The blood glucose level was determined using a Bayer Contour meter (Japan). Blood glucose level of more than $250 \mathrm{mg} / \mathrm{dL}$ is considered an indicator of diabetes mellitus incidence. Rats with blood glucose level of $250 \mathrm{mg} / \mathrm{dL}$ or more were chosen for the study (Francis and Sudha 2016).

\section{Preparation of ginger roots extract}

Dried ginger roots were purchased in Cairo, Egypt, from a local market of Agricultural Herbs, Spices, and Medicinal Plants. Ginger roots were authenticated at Cairo University Botany Department, Faculty of Science Herbarium. The air-dried ginger roots were ground into a fine powder with a blender before being subjected to aqueous extraction. Five hundred grams $(500 \mathrm{~g})$ of dried ginger roots were added to two liters $(2000 \mathrm{~mL})$ of distilled hot but not boiling water and shaken intermittently for three days. After that, the content was filtered to obtain a $25 \%$ aqueous ginger extract.

\section{Evaluation of the male fertility index}

The effect of GE on male fertility index was evaluated using a serial mating procedure. One treated male rat was mated with three normal females with a regular estrous cycle. Each male's fertility index was determined by dividing the number of females which become pregnant on the number of mated females with treated male rats as previously mentioned by Amann (1982).

\section{Experiment design and sampling}

Sixty mature (200-210g bwt and 3 months old) male Sprague-Dawley rats were randomly allocated into six groups of ten rats each. Group 1 served as a negative control, while the other groups were diabetic for 7 days after receiving a daily intraperitoneal injection of Streptozotocin at a dose of $50 \mathrm{mg} / \mathrm{kg}$. Group 2 was kept diabetic positive control, while groups 3 and 4 were orally given GE at 300 and $600 \mathrm{mg} / \mathrm{kg}$ for 65 consecutive days, respectively. Groups 5 and 6 were given the same doses of GE (300 and 600mg/kg) plus Vit. E @200mg/kg for the same period of time and by the same route. The dose of Vit. E used in this study for male rats was $200 \mathrm{mg} / \mathrm{kg}$ as mentioned by ELaraby et al. (2019). To cover the spermatogenic cycle of male rats, oral coadministration of GE and Vit. E was continued for 65 days (Amann 1982). At the end of the experiment, rats were with an anesthetized with an intraperitoneal anesthetic dose of $50 \mathrm{mg} / \mathrm{kg}$ pentobarbital sodium (Nesdonal ${ }^{\circledR} 10 \mathrm{~g}$ vials) and blood samples were withdrawn by puncture of the orbital plexus's veins of the eye. Serum samples were obtained by centrifugation for $15 \mathrm{~min}$ at $2200-2500 \mathrm{rpm}$ within one 
hour of blood collection and the kept frozen at $-20^{\circ} \mathrm{C}$. Testis, epididymis, and seminal vesicles were removed and weighed in relation to the animal's body weight.

\section{Examination of semen picture}

The cuda epididymis was cut and seminal contents of the epididymis were squeezed in a clean dry glass watch containing $2 \%$ sodium citrate solution. The seminal contents were microscopically examined for progressive motility, sperm cell count, viability (alive/dead) ratio and epididymal sperm cells abnormalities (Bearden and Fluquary 1980).

\section{Biochemical analysis}

Serum samples were used for estimation of blood glucose, insulin and male sex hormones (Testosterone, FSH, and LH) levels. BioMeriuex kit (Catalog No. 61269; BioMeriuex, Marcy l'Etoile, France) was obtained for determination of blood of glucose level according to Beach and Turner (1958) and insulin was measured as adopted by $\mathrm{Wu}$ et al. (2014). Testosterone concentrations were estimated using radioimmunoassay (RIA) method (Chen et al. 1994). While the concentrations of LH and FSH were estimated using ELISA technique according to Ballester et al. (2004).

\section{Histopathological examination}

Testicular specimens were collected and fixed in $10 \%$ neutral buffered formalin before being dehydrated in increasing concentrations of ethyl alcohol (70-100\%). Specimens were prepared using standard procedures of staining with H\&E (Luna 1968).

\section{Statistical analysis}

The data were presented as mean \pm SD. The one-way analysis of variance (ANOVA) test was used for the statistical analysis, followed by the Tukey test for multiple comparisons. The significance of differences between experimental groups was tested at a probability level of $\mathrm{P}<0.05$.

\section{RESULTS}

Diabetes mellitus induced by Streptozotocin in male rats decreased the fertility index to $50 \%$ versus $90 \%$ in negative normal control rats. Oral coadministration of GE at 300 and $600 \mathrm{mg} / \mathrm{kg}$ alone and combined with Vit. E at $200 \mathrm{mg} / \mathrm{kg}$ for 65 consecutive days increased the fertilizing capacity of male diabetic rats to $60,70,80$ and $80 \%$, respectively. Male diabetic rats administered $\mathrm{GE}$ at doses of 300 and $600 \mathrm{mg} / \mathrm{kg}$ combined with Vit. E $(200 \mathrm{mg} / \mathrm{kg})$ for 65 consecutive days significantly $(\mathrm{P}<0.05)$ increased weights of the testis and epididymis as depicted in Table 1. In addition, coadministration of GE at doses of 300 and $600 \mathrm{mg} / \mathrm{kg}$ and Vit. E to male rats for 65 consecutive days significantly $(\mathrm{P}<0.05)$ increased sperm cells count, progressive motility and viability (alive/dead) percent (Table 2). Sperm cells abnormalities in semen of male control positive diabetic rats were $12.5 \%$ versus to $3.9 \%$ of normal control rats. The sperm cell abnormalities of diabetic rats included detached head $(8.6 \%)$, double head $(1.0 \%)$, coiled head $(1.2 \%)$ and bent tail $(1.7 \%)$ as demonstrated in Fig. 1. Concurrent administration of rats with GE at 300 and $600 \mathrm{mg} / \mathrm{kg}$ and Vit. E decreased sperm cell abnormalities to 8.9 and $12.5 \%$ as compared to $12.5 \%$ of control positive diabetic rats.

Table 3 showed that rats which were given GE at 300 and $600 \mathrm{mg} / \mathrm{kg}$ along with Vit $\mathrm{E}$ for 65 days in a row, had lower blood glucose and insulin levels (hypoinsulinemia) than positive control diabetic rats. Serum testosterone, FSH, and LH levels were significantly increased in male rats given GE and Vit. E orally alone and concurrently for consecutive 65 days.

Histopathological examination of the testis of control negative rats revealed normal histological architecture of the seminiferous tubules, as shown in Fig. 2a. While testis of diabetic positive control rats showed mild to moderate spermatogenic cell degeneration, diffuse edema of interstitial cells, and complete spermatogenesis arrest in the majority of seminiferous tubules (Fig. 2b). However,

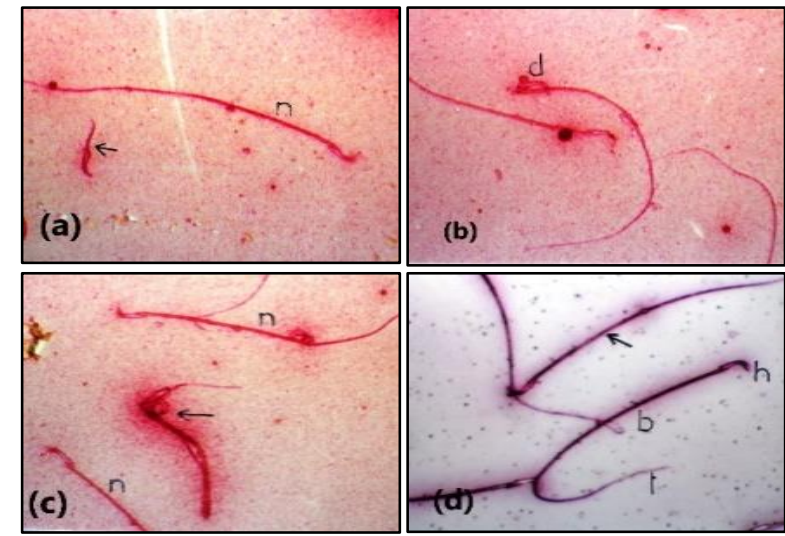

Fig. 1: Showing sperm cell abnormalities of positive control diabetic rats: (a) Detached head, (b) Double head, (c) Coiled head and (d) Bent tail. (Eosin-Nigrosine stain, X 200).

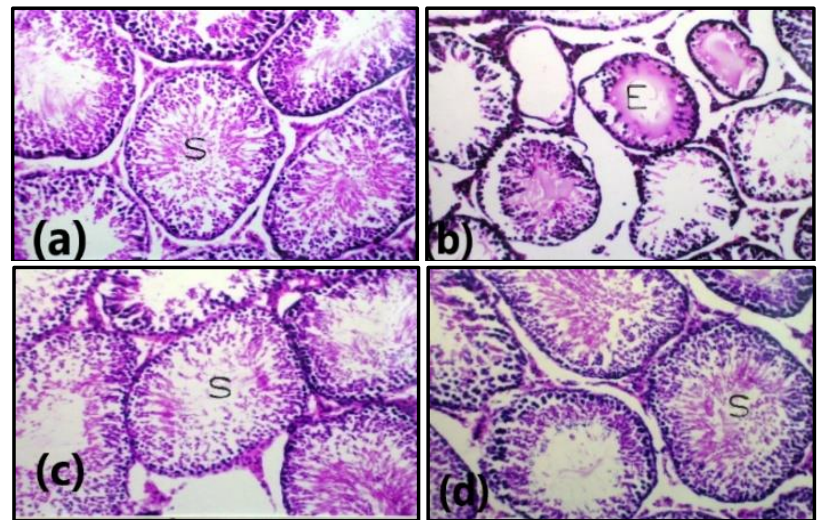

Fig. 2: Histopathological examination of the testis of normal control rats showed normal histological architecture of the seminiferous tubules (S) as illustrated in a) the testis of diabetic positive control rats showed mild to moderate degeneration of spermatogenic cells, diffuse edema (E) of interstitial cells and complete arrest of spermatogenesis in most of seminiferous tubules (b). The testis of diabetic rats given orally GE at $300 \mathrm{mg} / \mathrm{kg}$ concomitantly with Vit. E $(200 \mathrm{mg} / \mathrm{kg})$ revealed partial arrest of process of spermatogenesis in some of seminiferous tubules and the other seminiferous tubules were normal (c). The diabetic rats co-administered orally GE at $600 \mathrm{mg} / \mathrm{kg}$ plus Vit. E $(200 \mathrm{mg} / \mathrm{kg})$ showed that most of seminiferous tubules were normal and full of sperms and only few of them had partial arrest of spermatogenesis process (d). $\mathrm{H} \& \mathrm{E} \times 200$. 
Int J Vet Sci, 2022, 11(2): 183-188.

Table 1: Effect of oral administration of ginger extract (GE) alone and combined with Vit. E (200mg/kg) on weights of sexual organs of male diabetic rats $(\mathrm{n}=10)$

\begin{tabular}{lccc}
\hline Parameters Groups & Testes $(\mathrm{g})$ & Epididymis $(\mathrm{g})$ & Seminal Vesicles $(\mathrm{g})$ \\
\hline Negative control & $0.82 \pm 0.016 \mathrm{a}$ & $0.46 \pm 0.002 \mathrm{a}$ & $0.57 \pm 0.01 \mathrm{a}$ \\
Diabetic control & $0.56 \pm 0.014 \mathrm{~b}$ & $0.30 \pm 0.028 \mathrm{c}$ & $0.26 \pm 0.03 \mathrm{c}$ \\
GE $(300 \mathrm{mg} / \mathrm{kg})$ & $0.66 \pm 0.015 \mathrm{~b}$ & $0.33 \pm 0.018 \mathrm{~b}$ & $0.45 \pm 0.07 \mathrm{~b}$ \\
GE $(600 \mathrm{mg} / \mathrm{kg})$ & $0.68 \pm 0.001 \mathrm{~b}$ & $0.35 \pm 0.018 \mathrm{~b}$ & $0.46 \pm 0.04 \mathrm{~b}$ \\
GE $(300 \mathrm{mg} / \mathrm{kg})+$ Vit. E & $0.72 \pm 0.025 \mathrm{~b}$ & $0.39 \pm 0.019 \mathrm{~b}$ & $0.48 \pm 0.04 \mathrm{~b}$ \\
GE $(600 \mathrm{mg} / \mathrm{kg})+$ Vit. E & $0.79 \pm 0.016 \mathrm{a}$ & $0.41 \pm 0.002 \mathrm{a}$ & $0.49 \pm 0.01 \mathrm{a}$ \\
\hline
\end{tabular}

Mean \pm SD is a column bearing different letters differ significantly $(\mathrm{P}<0.05)$.

Table 2: Effect of oral administration ginger extract (GE) alone and combined with Vit. E on sperm cell characters of male diabetic rats $(\mathrm{n}=10)$

\begin{tabular}{lccc}
\hline Parameters Groups & Sperm cell count $\left(10^{6} / \mathrm{mL}\right)$ & Progressive Motility $(\%)$ & Viability $(\%)$ \\
\hline Negative control & $75.0 \pm 1.3 \mathrm{a}$ & $92.6 \pm 1.6 \mathrm{a}$ & $18.2 \pm 1.2 \mathrm{a}$ \\
Diabetic control & $45.0 \pm 1.4 \mathrm{~d}$ & $57.0 \pm 3.9 \mathrm{~d}$ & $6.6 \pm 1.4 \mathrm{~d}$ \\
GE $(300 \mathrm{mg} / \mathrm{kg})$ & $55.0 \pm 0.5 \mathrm{c}$ & $65.0 \pm 2.0 \mathrm{c}$ & $8.0 \pm 1.1 \mathrm{c}$ \\
GE $(600 \mathrm{mg} / \mathrm{kg})$ & $57.0 \pm 0.6 \mathrm{c}$ & $68.0 \pm 2.1 \mathrm{c}$ & $10.8 \pm 1.3 \mathrm{c}$ \\
GE $(300 \mathrm{mg} / \mathrm{kg})+$ Vit. E & $64.0 \pm 1.1 \mathrm{~b}$ & $72.0 \pm 0.8 \mathrm{~b}$ & $12.4 \pm 0.4 \mathrm{~b}$ \\
GE $(600 \mathrm{mg} / \mathrm{kg})+$ Vit. E & $66.0 \pm 1.2 \mathrm{~b}$ & $75.6 \pm 1.9 \mathrm{~b}$ & $13.2 \pm 1.2 \mathrm{~b}$ \\
\hline
\end{tabular}

Mean \pm SD with different letters in the same column differ significantly $(\mathrm{P}<0.05)$.

Table 3: Effect of oral administration ginger extract (GE) alone and combined with Vit. E (200mg/kg) on blood glucose (BG), insulin and sexual hormone levels of male diabetic rats $(\mathrm{n}=10)$

\begin{tabular}{lccccc}
\hline Groups & BG $(\mathrm{mg} / \mathrm{dL})$ & Insulin $(\mu \mathrm{U} / \mathrm{mL})$ & Testosterone $(\mathrm{ng} / \mathrm{mL})$ & FSH $(\mathrm{ng} / \mathrm{mL})$ & $\mathrm{LH}(\mathrm{ng} / \mathrm{mL})$ \\
\hline Negative control & $190 \pm 8.0 \mathrm{~d}$ & $10.95 \pm 0.15 \mathrm{a}$ & $2.95 \pm 0.04 \mathrm{a}$ & $2.80 \pm 0.03 \mathrm{a}$ & $0.57 \pm 0.01 \mathrm{a}$ \\
Diabetic control & $385 \pm 9.0 \mathrm{a}$ & $12.89 \pm 0.13 \mathrm{c}$ & $1.55 \pm 0.07 \mathrm{~d}$ & $1.72 \pm 0.05 \mathrm{~d}$ & $0.26 \pm 0.03 \mathrm{~d}$ \\
GE $(300 \mathrm{mg} / \mathrm{kg})$ & $300 \pm 6.0 \mathrm{~b}$ & $3.62 \pm 0.24 \mathrm{~b}$ & $2.94 \pm 0.07 \mathrm{c}$ & $1.80 \pm 0.04 \mathrm{c}$ & $0.45 \pm 0.07 \mathrm{~b}$ \\
GE $(600 \mathrm{mg} / \mathrm{kg})$ & $295 \pm 7.0 \mathrm{~b}$ & $3.63 \pm 0.12 \mathrm{~b}$ & $3.10 \pm 0.04 \mathrm{c}$ & $1.86 \pm 0.05 \mathrm{c}$ & $0.46 \pm 0.04 \mathrm{~b}$ \\
GE $(300 \mathrm{mg} / \mathrm{kg})+$ Vit. E & $227 \pm 5.0 \mathrm{c}$ & $2.75 \pm 0.14 \mathrm{~b}$ & $3.20 \pm 0.06 \mathrm{~b}$ & $2.10 \pm 0.03 \mathrm{~b}$ & $0.48 \pm 0.04 \mathrm{~b}$ \\
GE $(600 \mathrm{mg} / \mathrm{kg})+V i t . \mathrm{E}$ & $225 \pm 4.0 \mathrm{c}$ & $2.70 \pm 0.11 \mathrm{~b}$ & $3.40 \pm 0.06 \mathrm{~b}$ & $2.50 \pm 0.02 \mathrm{~b}$ & $0.49 \pm 0.01 \mathrm{~b}$ \\
\hline
\end{tabular}

Mean \pm SD with different letters in the same column differ significantly $(\mathrm{P}<0.05)$.

the testis of diabetic rats given orally $\mathrm{GE}$ at $300 \mathrm{mg} / \mathrm{kg}$ concomitantly with Vit. E revealed partial arrest of spermatogenesis in some of seminiferous tubules while, the other seminiferous tubules were normal (Fig. 2c). The diabetic rats administered orally GE at $600 \mathrm{mg} / \mathrm{kg}$ plus Vit. E showed that most of seminiferous tubules were normal and full of sperms and only few of them had partial arrest of spermatogenesis process (Fig. 2d).

\section{DISCUSSION}

This study was conducted to figure out the impact of coadministration of ginger extract (GE) and vitamin $\mathrm{E}$ (Vit. E) on the male fertility in Streptozotocin-induced diabetic rats. Streptozotocin was used in this study to induce diabetes mellitus in male rats as reported by Francis and Sudha (2016). Streptozotocin (STZ) is currently the most used diabetogenic agent in testing insulin and new antidiabetic drugs in animals (Quinna and Badwan 2015). The dose of STZ used in this study $50 \mathrm{mg} / \mathrm{kg}$ was similar to that previously used by Lenzen (2008). According to the later author, STZ causes pancreatic cell damage, resulting in and hyperglycemia and hypeinsulinemia. The mechanisms by which STZ induced testicular toxicity may be due to induction of oxidative stress and reduction of the activity of antioxidants enzymes (Zha et al. 2018). Also, Streptozotocin-induced testicular damage may be attributed to oxidative damage, inflammation, and apoptosis (Zahang et al. 2017 and Nna 2019).

Vitamin E (alpha-tocopherol) is a potent antioxidant that regulates the body's oxidation processes. According to Kurutas (2016), utilization of Vit. E can help to mitigate the harmful effects of oxidative stress caused by oxygen free radicals (ROS). It was reported that diabetes mellitus can cause deleterious effects on the testis and process of spermatogenesis in rats (Maresch et al. 2018). Furthermore, Khorramabadi et al. (2019) referred to the ability of Vitamins $\mathrm{E}$ and $\mathrm{C}$ to prevent oxidative damage in sperm DNA in the rat testis. ELaraby et al. (2019) reported that oral administration of Vit. E supplement at 500,1000 and $2000 \mathrm{mg} / \mathrm{kg}$ in rats for 90 days was safe for the testis

The current study found that coadministration of GE and Vit. E to male diabetic rats increased the fertility index, testis and epididymis weights, serum testosterone levels, and semen quality and quantity. There was a decrease in blood glucose levels and an increase in insulin levels. These results agreed with those obtained by Morakino et al. (2008) and Sief et al. (2021) who concluded that GE improves fertility in diabetic male rats due to its powerful antioxidant and androgenic properties According to Khaki et al. (2009) and Zahra and Abbas (2020), GE treatment dramatically enhanced sperm count, viability, motility, and serum total testosterone levels. These data suggested that ginger may help maintain healthy sperm parameters (Al-Kashef 2021). Recently, ginger extract had potential to improve semen quality and quantity in lead acetate-treated male rats (Banihani 2018; Odo et al. 2020). Moreover, Morakinyo et al. (2008) found that GE was significantly increase the relative weight of the rat testis as well as serum testosterone levels. The previous authors concluded that GE have an androgenic activity in rats. However, the improvement of 
semen quality and parameters of biochemical analysis agreed with alleviations of histopathological lesions seen in the testis of rats co-administered with GE and Vit. E (Al-Kashef 2021).

According to the previous findings, it could be assumed that mechanism (s) by which GE alleviated testicular lesions in diabetic rats may be attributed to its antioxidant, androgenic, and hypoglycemic effects. Also, co-administration of GE and Vit. E assisted to decline the hyperglycemic effect existed by STZ-induced diabetes. The hypoglycemic effect of ginger roots that reported herein agreed which that was reported by Nammi et al. (2009) who concluded that in rats fed a high-fat diet for 6 weeks, the blood glucose, insulin, total cholesterol, LDL cholesterol, triglycerides levels were significantly reduced by Zingiber officinale treatment rats. The authors concluded that GE has hypoglycemic, hypoinsulinemic, and regulates diabetes and dyslipidemia. Moreover, ginger have a protective effect against abnormalities in diabetic rats due to its antioxidant properties (Al-Qulaly 2021).

\section{Conclusion}

Coadministration of GE and Vit. E increased the fertility index, weights of the testis and epididymis, serum testosterone levels and improved the process of spermatogenesis in rats. It decreased blood glucose and insulin levels and alleviated testicular lesions seen in diabetic rat testis. GE and Vit. E improve male fertility in diabetic rats. According to findings of the current study, utilization of ginger roots as a boiled drink and intake of Vit. E as a dietary supplement may be beneficial to improve the fertility in male diabetic patients who suffering from sexual impotency.

\section{Acknowledgments}

The authors wish to thank Prof. Dr. Adel M. Bakeer, Professor of Pathology, Faculty of Veterinary Medicine, Cairo University, Egypt for his comments on histopathological work. Sincere thanks are also offered to Mr. Ahmed Elshabrawy, technician of Pharmacology Department for his caring of the rats.

\section{Author's Contribution}

MAS suggested the idea of the manuscript, planned the study and wrote the references. SRI performed the experimental part of this work. RAG examined the sperm cell characters and counted the sperms. All authors shared writing, drafting and approval of the manuscript.

\section{REFERENCES}

Abdel-Azeem AS, Hegazy AM, Ibrahim KS, Farrag AR and ElSayed EM, 2013. Hepatoprotective, antioxidant and ameliorative effects of ginger (Zingiber officinale) and vitamin $\mathrm{E}$ in acetaminophen-treated rats. Journal of Dietary Supplements 10: 195-209. https://doi.org/10.3109/ $\underline{19390211.2013 .822450}$

Al-Amin ZM, Thomson M, Al Qattan KK, Peltonen-Shalaby R and Ali M, 2017. Antidiabetic and hypolipidemic properties of ginger (Zingiber officinale) in Streptozotocin- induced diabetic rats. British Journal of Nutrition: 96: 660-666. https://doi.org/10.1079/bjn20061849
Al-Kashef MM, 2021. Effect of ginger on sexual performance and fertility of quail birds under semiarid condition. Egyptian Poultry Science Journal 41: 161-174.

Al-Qulaly MM, Okasha, MA Mohamed GM and Hassan MG, 2021. Effect of ginger and cinnamon on induced diabetes mellitus in adult male albino rat. Bulletin of Egyptian Society of Physiological Sciences 41: 373-388. https://doi.org/10.21608/BESPS.2020.45577.1078

Amann RP, 1982. Use of animal models for detecting specific alteration in reproduction. Fundamental of Applied Toxicology 2: 13-36. https://doi.org/10.1016/s0272-0590 (82)80059-6

Bakr AF, Abdelgayed SS, EL-Tawil OS and Bakeer AM, 2020. Ginger extract and ginger nanoparticles, characterization and applications. International Journal of Veterinary Science 9: 203-209. https://doi.org/10.37422/IJVS/20.021

Ballester J, Munoz MC, Dominguez J, Rigau T, Guinovart JJ and Rodriguez JE, 2004. Insulin-dependent diabetes affects testicular function by FSH- and LH-linked mechanisms. Journal of Andrology 25: 706-719. https://doi.org/10.1002/ j.1939-4640.2004.tb02845.x

Banihani SA, 2018. Ginger and testosterone: A review. Biomolecules 22: 119-125. https://doi.org/10.3390/biom $\underline{8040119}$

Banihani SA, 2019. Effect of ginger (Zingiber officinale) on semen quality. Andrologia 22: 1-7. https://doi.org/10.1111/ and.13296

Beach EF and Turner JJ, 1958. An enzymatic method for glucose determination in body fluids. Clinical Chemistry 4: 462-475. https://doi.org/10.1093/clinchem/4.6.462

Bearden HJ and Fluquary J, 1980. Applied Animal Reproduction. The $5^{\text {th }}$ Edition. Restore Publishing Co. Inc., Reston, VA, USA, pp: 158-160.

Bodagh MN, Maleki I and Hekmatdoost A, 2019. Ginger in gastrointestinal disorders: A systematic review of clinical trials. Food Sciences and Nutrition 7: 96-108. https://doi.org/10.1002/fsn3.807

Brezina PR, Fahd N, Yunus FN and Zhao Y, 2012. Effects of pharmaceutical medications on male fertility. Journal of Reproduction and Infertility 13: 3-11.

Chen H, Hardy MP, Aniemi IH and Zirkin BR, 1994. Agerelated decreased Leydig cells testosterone production in the Brown Norway rat. Journal of Andrology 15: 551-557. https://doi.org/10.1210/endo.134.5.8802

ELaraby EE. Heba NG, Hassan AK and Abbas OA, 2019. Effect of subchronic Vitamin $\mathrm{E}$ treatment on the testes of male albino rats. International Journal of Research Studies in Zoology 5: 15-19. https://doi.org/10.20431/2454-941X. $\underline{0502003}$

Eid BS, Mosli H, Hany M and El-Bassossy H, 2017. Ginger ingredients alleviate diabetic prostatic complications: Effect on oxidative stress and fibrosis. Evidence-Based Complementary Alternative Medicine 2017: 6090269. https://doi.org/10.1155/2017/6090269

Francis BT and Sudha S, 2016. Histopathological changes on Streptozotocin-induced diabetic rats following administration of polyherbal extract. A study on pancreas and kidney. World Journal Pharmacy and Pharmaceutical Sciences 5: 1188-1200. https://doi.org/10.20959/wjpps 201610-7898

Isidori AM, Pozza C, Gianfrilli D and Isidori A, 2006. Medical treatment to improve sperm quality. Journal of Reproduction and Biomedicine 12: 704-714. https://doi.org/ 10.1016/s1472-6483(10)61082-6

Joshua JK and Catherine CL, 2010. Ginger extract and polaprezinc exert gastroprotective actions by anti-oxidant and growth factor modulating effects in rats. Journal of Gastroenterology and Hepatology 25: 1861-1869. https://doi.org/10.1111/j.1440-1746.2010.06347.X 
Kanter M, Aktas C and Erboga M, 2012. Protective effects of quercetin against apoptosis and oxidative stress in Streptozotocin-induced diabetic rat testis. Food and Chemical Toxicology 50: 719-725. https://doi.org/10.1016/ j.fct.2011.11.051.

Khaki A, Fatemek F, Mohammad N, Amir AK, Chelar CO, Marefat N and Mohammad H, 2009. The effects of ginger on spermatogenesis and sperm parameters. Iranian Journal of Reproductive and Medicine 7: 7-12.

Khorramabadi MK, Talebi AR, Sarcheshmeh AA and Mirjalili A, 2019. Protective effect of vitamin E on oxidative stress and sperm apoptosis in diabetic mice. International Journal of Reproductive Medicine 17: 127-134. https://doi.org/ 10.18502/ijrm.v17i2.3990

Kurutas EB, 2016. The importance of antioxidants which play the role in cellular response against oxidative/nitrosative stress: current state. Journal of Nutrition 15: 71. https://doi.org/10.1186/s12937-016-0186-5

Lenzen S, 2008. The mechanisms of alloxan- and Streptozotocin-induced diabetes. Diabetologia 51: 216-226. https://doi.org/10.1007/s00125-007-0886-7

Lucchesi AN, Freitas NT, Cassettari LL, Marques SE and Spadella CT, 2013. Diabetes mellitus triggers oxidative stress in the liver of alloxan- treated rats: A mechanism for diabetic chronic liver disease. Acta Cirurgica Brasileria 28: 502-508. https://doi.org/10.1590/s0102-6502013000700005

Luis-Rodríguez D, Martínez-Castelao A, Gorriz JL, De-Alvaro F and Navarro-Gonzalez JF, 2012. Pathophysiological role and therapeutic implications of inflammation in diabetic nephropathy. World Journal of Diabetes 15: 7-18. https://doi.org/10.4239/wjd.v3.i17

Luna LG, 1968. Manual Histologic Staining Methods of the Armed Forces Institute of Pathology. $3^{\text {rd }}$ Ed, McGraw Hill Book Co., New York, USA, pp: 58.

Majeed Y, Shaukat MB, Abbasi KY and Ahmad MA, 2021. Indigenous plants of Pakistan for the treatment of diabetes: A review. Agrobiological Records 4: 44-63. https://doi.org/10.47278/journal.abr/2020.028

Maresch CC, Stute CD, Alves GM, Oliveira, PF, Ktertser DM and Linn T, 2018. Diabetes-induced hyperglycemia impairs male reproductive function: a systematic review. Human Reproductive Update 24: 86-105. https://doi.org/10.1093/ humupd/dmx033

Mascolo N, Jain R, Jain SC and Cappsso F, 1989. Ethnopharmacological investigation of ginger (Zingiber officinale). Journal of Ethnopharmacology 27: 129-140. https://doi.org/10.1016/0378- 8741(89)90085-8

Mekuriya W and Mekibib B, 2018. Review on the medicinal values of ginger for human and animal aliments. Journal of Veterinary Science and Technology 9: 1-5. https://doi.org/ $\underline{10.4172 / 2157-7579.1000519}$

Morakinyo AO, Adeniyi OS and Arikawe AP, 2008. Effects of Zingiber officinale on reproductive functions in the male rat. African Journal of Biomedical Research 11: 329-334. https://doi.org/10.4314/ajbr. v11i3.50750

Nammi S, Sreemantula S and Roufogalis BD, 2009. Protective effect of ethanolic extract of Zingiber officinale on the development of metabolic syndrome in high fat diet fed rats. Basic Clinical Pharmacology and Toxicology 104 366-373. https://doi.org/10.1111/j.1742-7843.2008.00362.x

Nna UV, Abu Baker AB, Ahmad A, Eleazu CO and Mohamed M, 2019. Oxidative stress, NF-kB-mediated inflammation and apoptosis in the testes of Streptozotocin-induced diabetic rats: Combined protective effects of Malaysian propolis and Metformin. Antioxidants 8: 465-470. https://doi.org/10.3390/antiox8100465

Odo RI, Mbegbu EC, Lawrence N and Anyanwu LN, 2020. Effect of aqueous ginger (Zingiber officinale) extract on sperm quality and hematology in lead acetate-treated male albino rats. Tropical Journal of Pharmaceutical Research 19: 1481-1485. https://doi.org/10.4314/tipr. v19i7.21

Quinna NA and Badwan, AA 2015. Impact of Streptozotocin on altering normal glucose homeostasis during insulin testing in diabetic rats compared to normoglycemic rats. Drug Design, Development and Therapy 9: 1515-1525. https://doi.org/10.2147/DDDT.S79885

Romero A, Forero M, Sequeda-Castaneda LG, Grismaldo A, Iglesias J, Celis-Zambrano CA, Schuler I and Morales L, 2018. Effect of ginger extract on membrane potential changes and akt activation on a peroxide- induced oxidative stress cell model. Journal of King Saud University Science 30: 263-269. https://doi.org/10.1016/j.jksus.2017.09.015

Shanmugam KR, Mallikarjuna K, Kesireddy N, Sathyavelu S and Reddy K, 2011. Neuroprotective effect of ginger on anti-oxidant enzymes in diabetic rats. Food and Chemical Toxicology 49: 893-897. https://doi.org/10.1016/j.fct. 2010. 12.013

Sief M, Abdel Aziz T, Aly M. and Wong Z, 2021. Zingiber officinale ethanolic extract Attenuates oxidative stress, steriodogenic activity and gene expression. Environmental Science and Pollution Research 28: 19783-19798. https://doi.org/10.1007/s11356-020-11509-1

Wang GG, Lu XH, Li W, Zhao X and Zhang C, 2011. Protective effects of Luteolin on diabetic nephropathy in STZ-induced diabetic rats. Evidence-Based Complementary and Alternative Medicine 8: 1-6. https://doi.org/10.1155/2011/323171

Wu C, Lin J, Hsia T, Hsu C, Chang J Chen J Chun Pei J, Pei D and Chen Y, 2014. Accurate method to estimate insulin resistance from multiple regression models using data of metabolic syndrome and oral glucose tolerance test. Journal of Diabetes Investigation 5: 290-296. https://doi.org/ $\underline{10.1111 / j d i .12155}$

Zahang M, Veinnois IF, Prasad M, Zhang Y, Wang L, Zhang Z, Han MK, Xiao B, Xu C, Srinivasan S and Merlin D, 2017. Edible ginger nanoparticles: A novel therapeutic approaches for the prevention and treatment of inflammatory bowel disease and colitis-associated cancer. Biomaterial 101: 321-340. https://doi.org/10.1016/j. biomaterials.2016.06.018

Zahra M and Abbas F, 2020. Ginger and Echinacea extracts improve the quality and fertility potential of frozen-thawed ram epididymal spermatozoa. Cryobiology 92: 138-145. https://doi.org/10.1016/j.cryobiol.2019.12.003.

Zha W, Bai Y, Xu L, Liu Y, Yang Z, Gao H and Li J, 2018. Curcumin attenuates testicular injury in rats with Streptozotocin-induced diabetes. Biomed Research International 4: 1-10. https://doi.org/10.1155/2018/7468019 